\title{
Activation of $\triangle F 508$ CFTR in a cystic fibrosis respiratory epithelial cell line by 4-phenylbutyrate, genistein and CPX
}

\author{
C. Andersson, G.M. Roomans
}

\begin{abstract}
Activation of $\triangle F 508-C F T R$ in respiratory epithelial cells by 4-phenylbutyrate, genistein and CPX. C. Andersson, G.M. Roomans. C ERS Journals Ltd 2000.

ABSTRACT: The cellular basis of cystic fibrosis (CF) is a defect in a cyclic adenosine monophosphate (cAMP)-activated chloride channel (CF transmembrane conductance regulator) in epithelial cells that leads to decreased chloride ion transport and impaired water transport across the cell membrane. This study investigated whether it was possible to activate the defective chloride channel in cystic fibrosis respiratory epithelial cells with 4-phenylbutyrate (4PBA), genistein and 8-cyclopentyl-1,3-dipropylxanthine (CPX).

The CF bronchial epithelial cell line CFBE41o-, which expresses the $\Delta F 508 \mathrm{mu}$ tation, was treated with these agents and loss of $\mathrm{Cl}^{-}$, indicating $\mathrm{Cl}^{-}$efflux, measured by $\mathrm{X}$-ray microanalysis.

8-bromo-cAMP alone did not induce $\mathrm{Cl}^{-}$efflux in CFBE410- cells, but after incubation with 4PBA a significant efflux of $\mathrm{Cl}^{-}$occurred. Stimulation of cells with a combination of genistein and cAMP also induced $\mathrm{Cl}^{-}$efflux, whereas a combination of pretreatment with $4 \mathrm{PBA}$ and a combined stimulation with genistein and cAMP induced an even larger $\mathrm{Cl}$ - efflux. $\mathrm{Cl}^{-}$efflux could also be stimulated by $\mathrm{CPX}$, but this effect was not enhanced by 4PBA pretreatment.

The $\Delta$ F508 mutation leads to impaired processing of the cystic fibrosis transmembrane conductance regulator. The increased efflux of chloride after 4-phenylbutyrate treatment can be explained by the fact that 4-phenylbutyrate allows the $\Delta$ F508 cystic fibrosis transmembrane conductance regulator to escape degradation and to be transported to the cell surface. Genistein and 8-cyclopentyl-1,3-dipropylxanthine act by stimulating chloride ion efflux by increasing the probability of the cystic fibrosis transmembrane conductance regulator being open. The combination of 4-phenylbutyrate and genistein may be useful in a potential pharmacological therapy for cystic fibrosis patients with the $\Delta$ F508 mutation.
\end{abstract}

Eur Respir J 2000; 15: 937-941.

Cystic fibrosis (CF) is a monogenic disease caused by a mutation in the gene that codes for the $\mathrm{CF}$ transmembrane conductance regulator (CFTR). The CFTR functions as a cyclic adenosine monophosphate (cAMP)-activated chloride channel that is regulated by phosphorylation of the regulatory domain by protein kinase $\mathrm{A}$ and $\mathrm{C}$ and by binding and hydrolysis of adenosine triphosphate at the two nucleotide-binding domains. The defective protein causes impaired chloride ion transport in epithelial cells. $\Delta$ F508 CFTR, the most common mutation in CF, results in a partially functional chloride channel with a decreased probability of being open. However, the mutation causes the retention of the CFTR in the endoplasmic reticulum(ER) so that it does not traffic properly to the plasma membrane.

There are several potential ways of bypassing this trafficking defect: stabilization of the protein by chemical chaperones [1], disruption of the interaction between $\Delta \mathrm{F} 508$ CFTR and a molecular chaperone, e.g. heat shock protein (Hsp)70 or calnexin that retains the mutant CFTR in the ER [2], overexpression of the mutant $\Delta$ F508 CFTR to allow it to escape the ER control system [3], or transcriptional regulation of proteins involved in the ER control system.

4-phenylbutyrate (4PBA) allows the $\Delta \mathrm{F} 508 \mathrm{CFTR}$ to be directed to the plasma membrane, possibly via effects on Hsp70 levels, assuming that 4PBA has the same effect as
Dept of Medical Cell Biology, University of Uppsala, Box 571, S-75123 Uppsala, Sweden.

Correspondence: C. Andersson, Dept of Medical Cell Biology, Uppsala University, Box 571, S-75123 Uppsala, Sweden. Fax: 4618551120

Keywords: Chloride transport cystic fibrosis

$\Delta$ F508-cystic fibrosis transmembrane

conductance regulator

genistein

4-phenylbutyrate

$\mathrm{X}$-ray microanalysis

Received: July 81999

Accepted after revision January 312000

This study was supported by grants from the Swedish Medical Research Council (project 07125), the Swedish Heart Lung Association and the Swedish Association for Cystic Fibrosis. butyrate [4]. 4PBA has been reported to correct the cAMP-mediated $\mathrm{Cl}^{-}$transport in primary cultures of nasal polyp epithelia from CF patients and in a CF cell line [5]. It also induces CFTR function in the nasal epithelia of $\Delta \mathrm{F} 508$-homozygous patients, as measured by nasal potential difference [6]. 4PBA can correct the trafficking defect, but correction of the chloride channel properties may also be necessary in clinical therapy. Genistein, a tyrosine kinase inhibitor abundant in legumes, is known to activate both wild-type and $\Delta$ F508 CFTR by increasing its probability of being open, probably by direct interaction with the CFTR [7-10]. 8-cyclopentyl-1,3-dipropylxanthine (CPX) is an adenosine $\mathrm{A}_{1}$-receptor antagonist that activates the $\Delta F 508$ CFTR and has been shown to bind to the nucleotide binding domain 1 of the CFTR [11].

It was hypothesized that genistein or CPX could enhance the effect of 4PBA on $\mathrm{Cl}^{-}$secretion from CF airway epithelial cells.

\section{Material and methods}

\section{Materials and solutions}

8-bromo-cAMP, genistein, CPX, fibronectin, collagen and bovine serum albumin (BSA) were from Sigma Chemical Co. (St Louis, MO, USA). 4PBA was from 
Triple Crown America (Perkasie, PA, USA). Standard Ringer's solution consisted of: $140 \mathrm{mM} \mathrm{NaCl}, 5 \mathrm{mM} \mathrm{KCl}$, $5 \mathrm{mM}$ (2-hydroxyethyl)- $N$-piperazine $N$-2 ethanesulphonic acid (HEPES), $1 \mathrm{mM} \mathrm{MgCl} 21.5 \mathrm{mM} \mathrm{CaCl}_{2}$ and $5 \mathrm{mM}$ glucose, $\mathrm{pH} 7.4$.

\section{Cell culture}

The CFBE41o- and 16HBE14o- cell lines, the generous gift of D.C. Gruenert, (University of California, San Francisco, CA, USA), were cultured in minimal essential medium with glutamax $524 \mathrm{mg} \cdot \mathrm{L}^{-1}$ (Gibco, BRL/Life Technologies, Paisley, UK) supplemented with $10 \%$ foetal bovine serum, $100 \mathrm{U} \cdot \mathrm{mL}^{-1}$ penicillin and $100 \mu \mathrm{g} \cdot \mathrm{mL}^{-1}$ streptomycin sulphate in $5 \%$ carbon dioxide in air at $37^{\circ} \mathrm{C}$. The culture flasks were coated with a solution containing $0.01 \mathrm{mg} \cdot \mathrm{mL}^{-1}$ fib-ronectin, $0.029 \mathrm{mg} \cdot \mathrm{mL}^{-1}$ collagen and $0.1 \mathrm{mg} \cdot \mathrm{mL}^{-1} \mathrm{BSA}$ for $\geq 1 \mathrm{~h}$ before seeding the cells. The medium was changed twice weekly.

\section{X-ray microanalysis}

Cells were cultured to confluence on titanium grids covered with a carbon-coated Formvar film (Merck, Darmstadt, Germany) coated with the fibronectin, collagen, and BSA solution (see Cell culture). Cells were incubated with or without 4PBA in Dulbecco's modified Eagle's medium:Ham's F12 medium (1:1) with glutamax (524 mg. $\left.\mathrm{L}^{-1}\right)$, $2 \%$ Ultroser $\mathrm{G}$ (Gibco, BRL/Life Technologies) and 50 $\mu \mathrm{g} \cdot \mathrm{mL}^{-1}$ gentamicin for $72 \mathrm{~h}$. The cells were then stimulated with $5 \mathrm{mM} 8$ 8-bromo-cAMP or $5 \mathrm{mM} 8$-bromo-cAMP and $50 \mu \mathrm{M}$ genistein for $3 \mathrm{~min}$ or with $30 \mathrm{nM}$ CPX for 15 min in standard Ringer's solution. The cells were rinsed with cold distilled water for some seconds before being frozen in liquid propane cooled by liquid nitrogen $\left(-180^{\circ} \mathrm{C}\right)$ and freeze-dried overnight under vacuum at $-120^{\circ} \mathrm{C}$. The freeze-dried cells were coated with a conductive carbon layer before analysis. Genistein and CPX were prepared from stock solutions in dimethyl sulphoxide (DMSO). The concentration of DMSO to which the cells were exposed was $\leq 1 \%$. No changes in the concentrations of the various elements measured were seen in the cells after exposure to $1 \%$ DMSO for 3 and $15 \mathrm{~min}$. Cells incubated with standard Ringer's solution (3 or $15 \mathrm{~min}$ ) were used as control.

Analysis was performed using a Hitachi H7100 electron microscope (Hitachi, Tokyo, Japan) in the scanning transmission electron microscopy mode at $100 \mathrm{kV}$ with an Oxford Instruments ISIS energy-dispersive spectrometer system (Oxford Instruments, Oxford, UK). Quantitative analysis was performed by comparing the ratio of the characteristic peak and the background under the peak (P:B) with the P:B of standards consisting of a gelatin/ glycerol matrix with mineral salts in known concentrations [12]. Spectra were acquired for $100 \mathrm{~s}$ and each cell was analysed only once.

\section{Statistical analysis}

One-way analysis of variance and Newman-Keuls multiple comparison post hoc test were used to evaluate statistical significance when more than two groups were compared. When two groups were compared, an unpaired t-test was used. Significance was attributed to a $p$-value of $<0.05$.

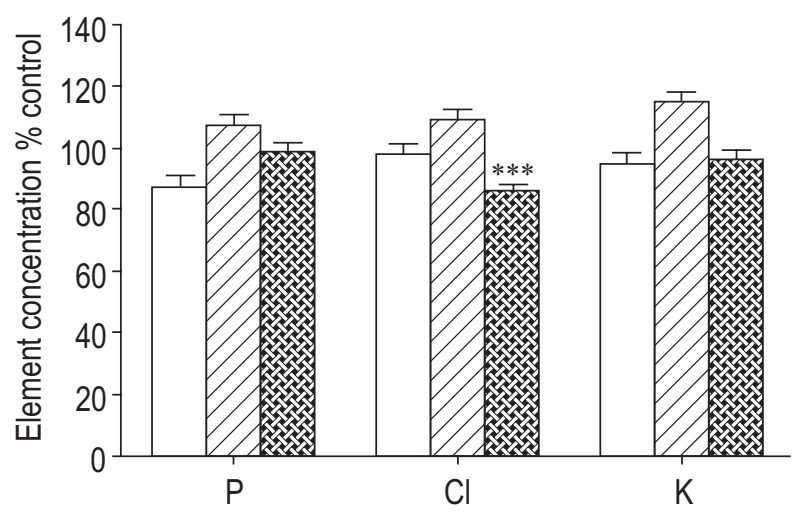

Fig. 1. - Effects of 8-bromo-cyclic adenosine monophosphate (8bromo-cAMP), 4-phenylbutyrate (4BPA, $\mathbb{Z}$ ) and the combination of 8-bromo-cAMP and 4BPA ( levels in CFBE41o- cells. The data are presented as mean \pm SEM from three to six experiments with 62 measurements on control cells, 28 on 8 bromo-cAMP-stimulated cells, 45 on 4BPA-treated cells and 77 on cells treated with the combination of 4BPA and 8-bromo-cAMP. $* * *:$ p $<$ 0.001 versus control.

\section{Results}

Incubation with 4PBA or stimulation with 8-bromocAMP alone did not affect the cellular content of phosphorus, chlorin or potassium in CFBE41o- cells, but, after incubation with 4PBA, 8-bromo-cAMP caused a significant decrease in the chlorine content (fig. 1). An X-ray spectrum of the cells is shown in figure 2. Stimulation of cells with a combination of genistein and 8-bromo-cAMP reduced the chlorine content of the cells, and a combination of pretreatment with 4PBA and stimulation with genistein and cAMP together induced an even larger decrease in chlorine content (fig. 3). CPX significantly reduced the chlorine content but 4PBA did not enhance this effect (fig. 4). The chlorine content of the control cells was stable for $\geq 15 \mathrm{~min}$. The data for phosphorous, an element for which no significant changes were expected, are provided as an "internal control".

In order to determine whether the secretion of $\mathrm{Cl}^{-}$in $\mathrm{CF}$ cells is of physiological relevance, a normal human bronchial epithelial cell line expressing the CFTR, 16HBE14o-, was stimulated with 8-bromo-cAMP (fig. 5). The decrease

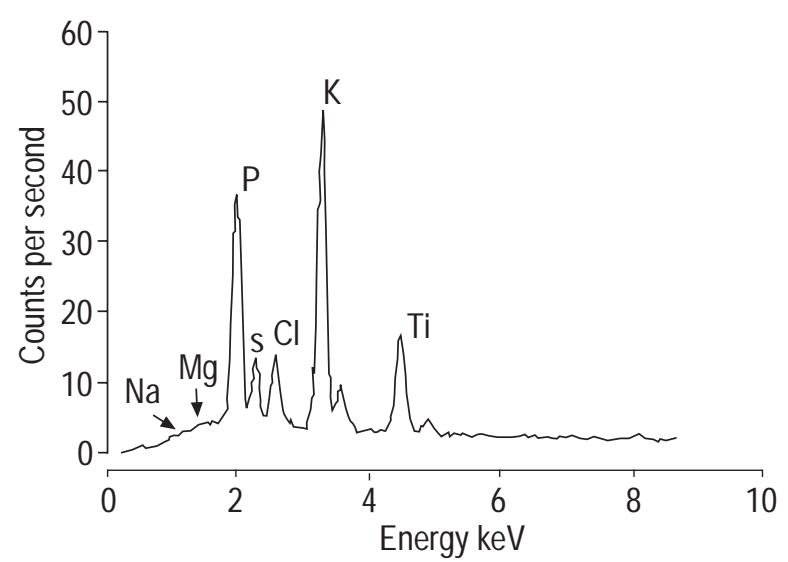

Fig. 2. - X-ray spectrum of CFBE41o- cells showing the characteristic peaks for sodium, magnesium, phosphorus, sulphur, chlorine, potassium and titanium. The Ti peak is due to the grid. 


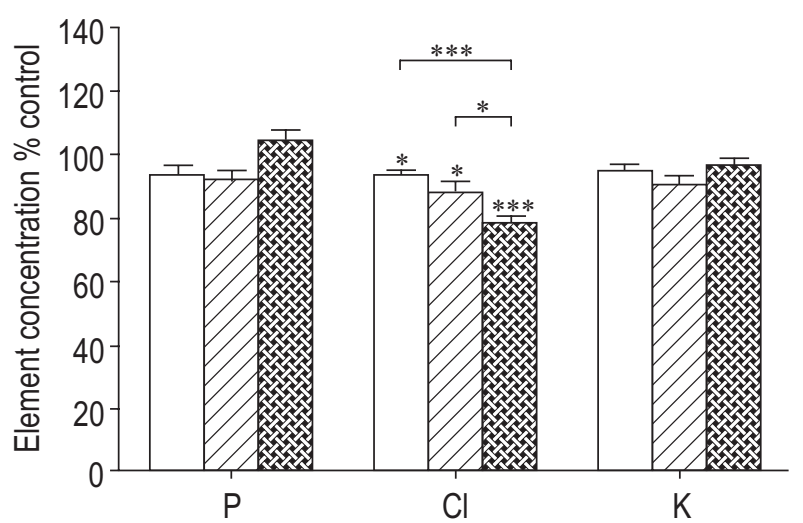

Fig. 3. - Effects of 4-phenylbutyrate (4BPA), genistein and 8-bromocyclic adenosine monophosphate (cAMP) (8-bromo-cAMP) on phosphorus, chlorine and potassium levels in CFBE41o- cells. Data are presented as mean \pm SEM from four to eight experiments with 96 measurements on 8-bromo-cAMP and genistein ( $\square$ ), 59 on cells stimulated with 4PBA and cAMP $(\mathbb{Z})$ and 87 on cells stimulated with 4PBA, 8bromo-cAMP and genistein (雄). *: $\mathrm{p}<0.05$; ***: $\mathrm{p}<0.001$ versus 8bromo-cAMP or between columns indicated.

in $\mathrm{Cl}^{-}$after stimulation with 8-bromo-cAMP in 16HBE140 - cells was $26 \%$. This can be compared with a $15 \%$ decrease after incubation with 4PBA, a $22 \%$ decrease on stimulation with genistein and cAMP after incubation with 4PBA, and a $13 \%$ decrease after stimulation with CPX (fig. 6).

\section{Discussion}

The experimental results in this study indicate that correction of the cAMP-dependent $\mathrm{Cl}^{-}$secretion by treatment with 4PBA can be further improved by genistein, an agent that increases the probability of the $\Delta$ F508 CFTR being open. Also, CPX increased $\mathrm{Cl}^{-}$secretion in CFBE41ocells.

It was found that the transcriptional regulator 4PBA increased $\mathrm{Cl}^{-}$secretion in the CFBE410- cell line, which expresses the $\Delta \mathrm{F} 508 \mathrm{CFTR}$ mutation. This is consistent with previous results with another CF cell line and primary

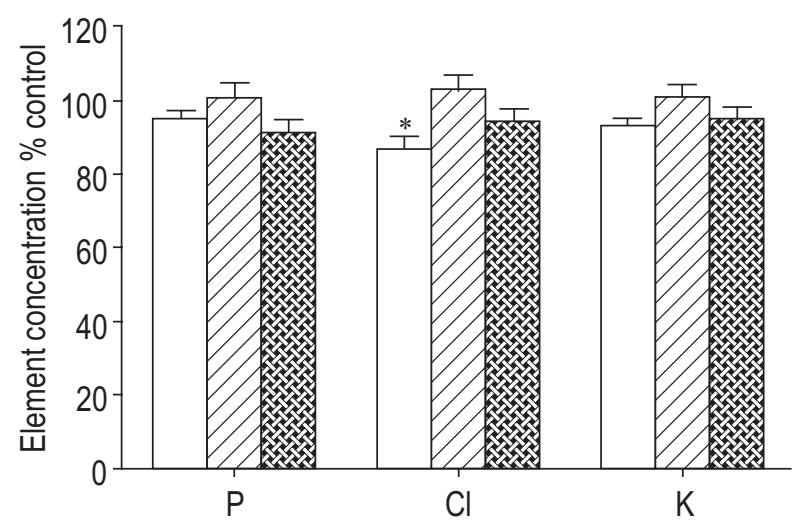

Fig. 4. - Effects of 8-cyclopentyl-1,3=dipropylxanthine (CPX) and 4phenylbutyrate (4PBA) on CFBE41o- cells. Data are presented as mean \pm SEM from four to six experiments with 43 measurements on control cells, 60 on cells stimulated with CPX $(\square), 43$ on cells treated with 4BPA and 38 on cells treated with 4BPA and CPX (瓷). $*$ : p $<0.05$ versus control.

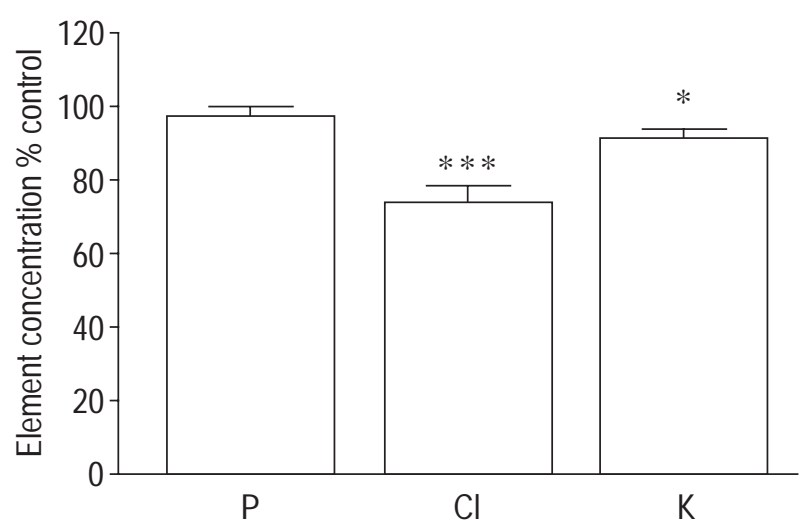

Fig. 5. - Effects of 8-bromo-cyclic adenosine monophosphate (8bromo-cAMP) on 16HBE14o- cells. Data are presented as mean \pm SEM from three experiments with 26 measurements on control cells and 48 on 8-bromo-cAMP-stimulated cells. *: $\mathrm{p}<0.05 ; * * *$ : $<<0.001$ versus control.

CF epithelial cell cultures [5]. The effect of the xanthine CPX and the isoflavone genistein on the CF cell line was investigated and this treatment combined with $4 \mathrm{PBA}$ to see whether the effect of 4PBA could be further improved.

$\mathrm{CPX}$ induced $\mathrm{Cl}^{-}$secretion in the CFBE41o- cell line, which is consistent with previous studies on CF cell lines [13], but an increase of this effect after incubation with 4PBA was not seen in the present study. The mechanism by which CPX activates $\mathrm{Cl}^{-}$efflux is not clear. CPX has been shown to bind to the first nucleotide-binding fold in $\triangle$ F508 CFTR [11]. Other studies argue against a direct activation of CFTR [14] and suggest that the CPX-induced $\mathrm{Cl}^{-}$efflux is related to CPX induced changes in intracellular $\mathrm{pH}[14,15]$. Since 4PBA did not increase the effect of CPX, the present data do not support a direct effect of CPX on $\triangle \mathrm{F} 508$ CFTR.

Genistein potentiates cAMP-dependent activation of $\triangle$ F508 CFTR [8]. The present results confirm that genistein induces the cAMP-dependent activation of $\Delta \mathrm{F} 508$

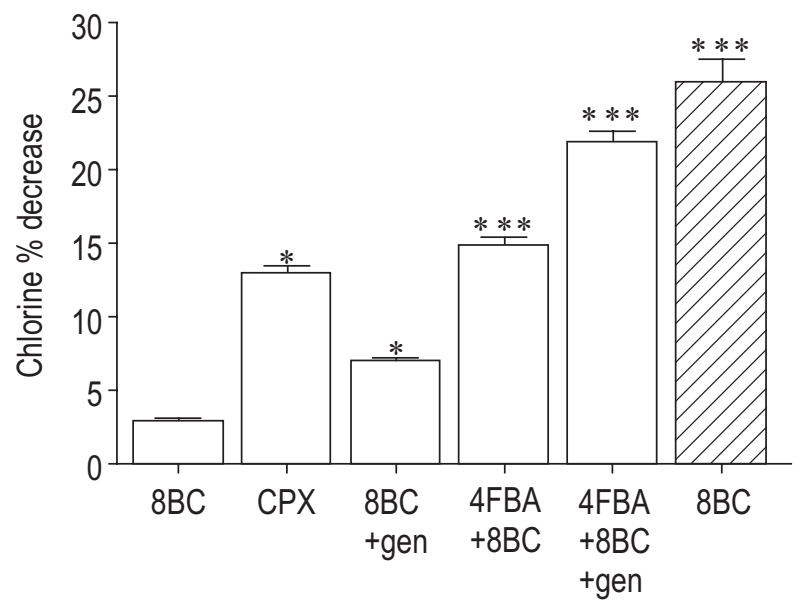

Fig. 6. - Effect of stimulation with various drugs on chlorine concentration in cystic fibrosis $(\square)$ and normal $(\mathbb{\mathbb { Q }})$ cells. Data are presented as mean \pm SEM. 8 BC: 8-bromo-cyclic adenosine monophosphate; CPX: 8cyclopentyl-1,3-dipropylxanthine; gen: genistein; 4PBA: 4-phenylbutyrate. $*$ : $\mathrm{p}<0.05 ; * * *: \mathrm{p}<0.001$ versus control. 
CFTR and suggests further that it is able to increase the $\mathrm{Cl}^{-}$secretion achieved after incubation with 4PBA.

It has previously been shown, by X-ray microanalysis, that loss of cellular chlorine (equivalent to $\mathrm{Cl}^{-}$efflux) occurs after stimulation with cAMP (analogues) in, for example, airway epithelial cells [16], tracheal gland cells [17] and sweat gland cells [18] containing the CFTR channel. This loss was absent in airway epithelial cells from CF patients [16], tracheal gland cells treated with antisense CFTR [17] and sweat gland cells and tracheal gland cells in the presence of chloride channel blockers [17-19]. Therefore, X-ray microanalysis is a useful technique for determining $\mathrm{Cl}^{-}$efflux. The technique gives data in $\mathrm{mmol} \cdot \mathrm{kg}$ dry weight ${ }^{-1}$, which may make the data difficult to interpret in a physiological context. However, by making assumptions about the water content, the data can be converted by approximation to millimolarity, which is the more usual unit for physiological investigations.

The chlorine and potassium content of the CFBE41ocell line was $\sim 190 \mathrm{mmol} \cdot \mathrm{kg}$ dry weight $^{-1}$ and $\sim 900$ $\mathrm{mmol} \cdot \mathrm{kg}$ dry weight ${ }^{-1}$ respectively. Assuming that $\sim 80 \%$ of the cell is water, these values are equivalent to $\sim 48 \mathrm{mM}$ intracellular $\mathrm{Cl}^{-}$and $225 \mathrm{mM}$ intracellular $\mathrm{K}^{+}$. The $26 \%$ decrease in $\mathrm{Cl}^{-}$in the normal cells expressing the CFTR after 8-bromo-cAMP stimulation is therefore equivalent to a $12 \mathrm{mM}$ decrease in $\mathrm{Cl}^{-}$. It is expected that $\mathrm{Cl}^{-}$efflux is accompanied by $\mathrm{K}^{+}$efflux. In all experiments, the potassium concentrations in the cells that show chloride efflux are lower than in the control cells by $\sim 40-50 \mathrm{mmol} \cdot \mathrm{kg}$ dry weight ${ }^{-1}$, or practically the same as the $\mathrm{Cl}^{-}$efflux. This means that there is no need to invoke mechanism other than $\mathrm{Cl}^{-}$efflux accompanied by a stoichiometric $\mathrm{K}^{+}$efflux to maintain electroneutrality and it is not necessary to assume, for example, $\mathrm{Cl}^{-} /$bicarbonate exchange. However, this efflux of $\mathrm{K}^{+}$is so small relative to the high $\mathrm{K}^{+}$content of the cells $(\sim 5 \%)$ that a significant decrease in potassium content could only be seen in the experiment shown in figure 5 .

The effect achieved by 4PBA, genistein and CPX on the $\mathrm{CF}$ cell line was compared with the effect of 8-bromocAMP on human bronchial epithelial cells expressing the wild-type CFTR. With 4PBA (15\% decrease), genistein ( $7 \%$ decrease) and CPX (13\% decrease) the reduction in $\mathrm{Cl}^{-}$concentration in the cells is less than the $26 \%$ decrease achieved by cAMP in the normal cells. However, combined treatment with $4 \mathrm{PBA}$ and genistein, with a reduction in $\mathrm{Cl}^{-}$concentration of $22 \%$, is comparable with the decrease achieved in normal cells (fig. 6). Many groups have shown that genistein increases the probability of the $\triangle F 508$ CFTR being open and have suggested a direct action of genistein on the CFTR [7-9]. Genistein increases the phosphorylation level of the regulatory domain $[8,20]$ without increasing cAMP levels or protein kinase A activity [20, 21]. Furthermore, it prevents deactivation of the channel after removal of cAMP-inducing stimulation $[21,22]$. This can be explained by inhibition of the dephosphorylation of the regulatory domain that inactivates the channel. Genistein increases the phosphorylation level of the CFTR but also increases the activity of the channel independent of the phosphorylation level [8].

4-phenylbutyrate directs more $\Delta \mathrm{F} 508$ cystic fibrosis transmembrane conductance regulator to the cell membrane. Genistein can act on these channels to increase the open time and supplement the effect achieved with 4phenylbutyrate. 4-phenylbutyrate is already in clinical use as an ammonia scavenger to treat urea cycle enzyme deficiencies. Genistein is a soy isoflavone that has been suggested to prevent cancer [23, 24] and atherosclerosis [25]. It would therefore be interesting to consider the therapeutic potential of a combination of 4-phenylbutyrate and genistein or genistein-like drugs as a pharmacological treatment for cystic fibrosis.

Acknowledgements. The technical assistance of A. Ahlander, M. Ljungkvist and L. Ljung is gratefully acknowledged.

\section{References}

1. Brown CR, Hong-Brown LQ, Biwersi J, Verkman AS, Welch WJ. Chemical chaperones correct the mutant phenotype of the $\Delta \mathrm{F} 508$ cystic fibrosis transmembrane conductance regulator protein. Cell Stress Chaperones 1996; 1: $117-125$.

2. Pind S, Riordan JR, Williams DB. Participation of the endoplasmic reticulum chaperone calnexin (p88, IP90) in the biogenesis of the cystic fibrosis transmembrane conductance regulator. J Biol Chem 1994; 269: 1278412788.

3. Cheng SH, Fang SL, Zabner J, et al. Functional activation of the cystic fibrosis trafficking mutant $\Delta$ F508-CFTR by overexpression. Am J Physiol 1995; 268: L615-L624.

4. Garcia-Bermejo L, Vilaboa NE, Perez C, Galan A, De Blas E, Aller P. Modulation of heatshock protein 70 (HSP70) gene expression by sodium butyrate in U-937 promonocytic cells: relationships with differentiation and apoptosis. Exp Cell Res 1997; 236: 268-274.

5. Rubenstein RC, Egan ME, Zeitlin PL. In vitro pharmacologic restoration of CFTR-mediated chloride transport with sodium 4-phenylbutyrate in cystic fibrosis epithelial cells containing $\Delta$ F508-CFTR. J Clin Invest 1997; 100: 2457-2465.

6. Rubenstein RC, Zeitlin PL. A pilot clinical trial of oral sodium 4-phenylbutyrate (Buphenyl) in $\Delta \mathrm{F} 508$-homozygous cystic fibrosis patients: partial restoration of nasal epithelial CFTR function. Am J Respir Crit Care Med 1998; 157: 484-490.

7. French PJ, Bijman J, Bot AG, Boomaars WE, Scholte BJ, de Jonge HR. Genistein activates CFTR $\mathrm{Cl}^{-}$channels via a tyrosine kinase- and protein phosphatase-independent mechanism. Am J Physiol 1997; 273: C747-C753.

8. Hwang TC, Wang F, Yang IC, Reenstra WW. Genistein potentiates wild-type and $\triangle \mathrm{F} 508$-CFTR channel acti-vity. Am J Physiol 1997; 273: C988-C998.

9. Wang F, Zeltwanger S, Yang IC, Nairn AC, Hwang TC. Actions of genistein on cystic fibrosis transmembrane conductance regulator channel gating. Evidence for two binding sites with opposite effects. J Gen Physiol 1998; 111: 477-490.

10. Weinreich F, Wood PG, Riordan JR, Nagel G. Direct action of genistein on CFTR. Pflugers Arch 1997; 434: 484-491.

11. Cohen BE, Lee G, Jacobson KA, et al. 8-cyclopentyl-1, 3-dipropylxanthine and other xanthines differentially bind to the wild-type and $\Delta \mathrm{F} 508$ first nucleotide binding fold (NBF-1) domains of the cystic fibrosis transmembrane conductance regulator. Biochemistry 1997; 36: 6455-6461. 
12. Roomans GM. Quantitative X-ray microanalysis of biological specimens. J Electron Microsc Tech 1988; 9: 1943.

13. Eidelman $\mathrm{O}$, Guay-Broder $\mathrm{C}$, van Galen PJ, et al. $\mathrm{A}_{1}$ adenosine-receptor antagonists activate chloride efflux from cystic fibrosis cells. Proc Natl Acad Sci USA 1992; 89: 5562-5566.

14. Kunzelmann K, Briel M, Schreiber R, Ricken S, Nitschke $\mathrm{R}$, Greger R. No evidence for direct activation of the cystic fibrosis transmembrane conductance regulator by 8 - cyclopentyl - 1,3 - dipropylxanthine. Cell Physiol Biochem 1998; 8: 185-193.

15. Casavola V, Turner RJ, Guay-Broder C, Jacobson KA, Eidelman O, Pollard HB. CPX, a selective $\mathrm{A}_{1}$-adenosinereceptor antagonist, regulates intracellular $\mathrm{pH}$ in cystic fibrosis cells. Am J Physiol 1995; 269: C226-C233.

16. Sagstrom S, Roomans GM, Wroblewski R, Keulemans JL, Hoogeveen AT, Bijman J. X-ray micro-analysis of cultured respiratory epithelial cells from patients with cystic fibrosis. Acta Physiol Scand 1992; 146: 213-220.

17. Zhang AL, Roomans GM. Multiple intracellular pathways for regulation of chloride secretion in cultured pig tracheal submucosal gland cells. Eur Respir J 1999; 13: 571-576.

18. Mork AC, Hongpaisan J, Roomans GM. Ion transport in primary cultures from human sweat gland coils studied with X-ray microanalysis. Cell Biol Int 1995; 19: 151159.

19. Hongpaisan J, Roomans GM. Regulation of ion content in primary cultures from reabsorptive ducts of human sweat glands studied by X-ray microanalysis. Cell Struct Funct 1998; 23: 239-245.

20. Reenstra WW, Yurko-Mauro K, Dam A, Raman S, Shorten S. CFTR chloride channel activation by genistein: the role of serine/threonine protein phosphatases. $\mathrm{Am} \mathrm{J}$ Physiol 1996; 271: C650-C657.

21. Illek B, Fischer H, Machen TE. Alternate stimulation of apical CFTR by genistein in epithelia. Am J Physiol 1996; 270: C265-C275.

22. Yang IC, Cheng TH, Wang F, Price EM, Hwang TC. Modulation of CFTR chloride channels by calyculin A and genistein. Am J Physiol 1997; 272: C142-C155.

23. Barnes S, Sfakianos J, Coward L, Kirk M. Soy isoflavonoids and cancer prevention. Underlying biochemical and pharmacological issues. Adv Exp Med Biol 1996; 401: 87-100.

24. Lian F, Li Y, Bhuiyan M, Sarkar FH. pS3-independent apoptosis induced by genistein in lung cancer cells. Nutr Cancer 1999; 33: 125-131.

25. Anthony MS, Clarkson TB, Williams JK. Effects of soy isoflavones on atherosclerosis: potential mechanisms. $\mathrm{Am}$ J Clin Nutr 1998; 68: 1390S-1393S. 